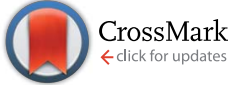

Cite this: J. Mater. Chem. A, 2014, 2 , 16632

Received 4th April 2014

Accepted 20th June 2014

DOI: $10.1039 / c 4 t a 01655 f$

www.rsc.org/MaterialsA

\section{Polyaromatic-hydrocarbon-based carbon copper composites for the suppression of electromagnetic pollution $\uparrow$}

\begin{abstract}
Anil Kumar, ${ }^{\text {ab }}$ A. P. Singh, ${ }^{a}$ Saroj Kumari, ${ }^{a}$ P. K. Dutta, ${ }^{\text {b }}$ S. K. Dhawan ${ }^{a}$ and Ajay Dhar ${ }^{\star a}$
A facile method of developing carbon-copper ( $\mathrm{C}-\mathrm{Cu}$ ) nanocomposites by coating nanocrystalline $\mathrm{Cu}$ on heat-treated polyaromatic hydrocarbons (HTPAHs) has been reported. These synthesized nanocomposites have been extensively characterized by X-ray diffraction, Fourier transform infrared spectroscopy (FTIR), a scanning electron microscope (SEM), and transmission electron microscopy (TEM). The synthesized HTPAHs-based $\mathrm{C}-\mathrm{Cu}$ nanocomposites exhibit improved mechanical and electrical properties, which could be tailored by varying the $\mathrm{Cu}$ nanoparticle loading. The highest electromagnetic interference shielding effectiveness (EMI SE) due to absorption and reflection at $12.4 \mathrm{GHz}$ is $46.1 \mathrm{~dB}$ and $12.5 \mathrm{~dB}$, respectively, for a $2 \mathrm{~mm}$ thick sample resulting in a total shielding effectiveness of $58.7 \mathrm{~dB}$. This observed shielding effectiveness in these $\mathrm{C}$-Cu nanocomposites is far above the threshold shielding effectiveness required for techno-commercial applications, especially in the Ku band of RF.
\end{abstract}

\section{Introduction}

Electromagnetic interference (EMI) is receiving a lot of scientific attention all over the world, ${ }^{1}$ due to the increasing proliferation of electronic devices in many sectors, including, satellite communication, radar surveillance systems, digital devices, wireless technology, ${ }^{2-4}$ etc. Besides this, EMI in daily life is also harmful under certain environments. ${ }^{5}$ Research efforts are being spearheaded in the military aviation and aerospace sectors, where the effective shielding of sensitive electronic equipment is critical. However, there are several additional requirements for EMI shielding materials over just shielding effectiveness, which are light weight, flexible, and produced on large scale, especially when targeting aviation and aerospace applications. Early initiatives to handle this novel kind of pollution have triggered a quest for efficient countermeasures to ensure the unperturbed performance of electronic equipment even in the presence of external EM noise. ${ }^{6,7}$ The increasing use of light-weight carbon-based composites as EMI shielding materials has emerged over the last decade as they possess an excellent combination of mechanical and electrical properties, and flexibility, coupled with s high aspect ratio. ${ }^{\mathbf{8 , 9}}$

${ }^{a}$ Material Physics and Engineering Division, CSIR-National Physical Laboratory, Dr K.
S. Krishnan Marg, New Delhi-110 012, India. E-mail: adhar@nplindia.org; Fax: +91-
11-45609310; Tel: +91-11-45609456
${ }^{b}$ Department of Chemistry, MN National Institute of Technology, Allahabad-211004,
India

$\dagger$ Electronic supplementary information (ESI) available. See DOI: $10.1039 / \mathrm{c} 4 \mathrm{ta} 01655 \mathrm{f}$
Various forms of highly conducting carbon, namely carbon nanotubes, ${ }^{10}$ graphene, ${ }^{11}$ carbon foam ${ }^{12,13}$ etc., have been so far employed to achieve high EMI shielding. It has been observed that the EMI SE, permittivity, and electrical conductivity of the nanocomposites developed using different carbon fillers in polymeric materials decreased as per the order: multi-walled carbon nanotubes (MWCNTs) > carbon nanofibres $>$ structure carbon black. ${ }^{14}$ Moreover, it has also been reported that a dispersion of metal nanoparticles, like silver, gold, copper, nickel, etc., form a strong conductive interconnect network in the carbon matrix, which enhances the electrical conductivity and the EMI shielding of the resulting composite. ${ }^{1,15,16}$ For instance, the EMI SE of polyaniline (PANI) composite filled with silver decorated (5.0 wt\% loading) graphene was reported to be $29.33 \mathrm{~dB}$, which was attributed to an enhancement in electrical conductivity due to the metal nanoparticle decoration and due to the high permittivity of the composites, and it was also observed that absorption was the governing factor for the improved EMI shielding. ${ }^{17}$ However, very few attempts have been made to introduce metallic nanoparticles in different carbon forms to the preparation of such composites. ${ }^{18-21}$ Shinnshuong et al. reported ${ }^{22}$ an EMI shielding $\sim 30 \mathrm{~dB}$ in copper/ nickel-coated fiber reinforced composites, developed by the electroless technique. These composites, when prepared by a conventional powder metallurgy technique, pose a big challenge for interfacial bonding, due to the lattice mismatch and poor wetting ability between the metal and different forms of carbon materials, resulting in inferior mechanical and electrical $^{23}$ properties. Although, in some cases the lack of wettability between the metal (for example, $\mathrm{Cu}$ ) and graphitic form of carbon has been found to be improved by suitably 
coating the metal using the electroless technique before consolidation. $^{24,25}$

In some reported studies, heat-treated polyaromatic hydrocarbons $^{26}$ (HTPAHs) have been used as a precursor material for the synthesis of synthetic graphite, ${ }^{27}$ as compared to natural graphite, leading to a high density and strength in the resulting composite. The HTPAHs-derived carbon and its resulting nanocomposite with $\mathrm{Cu}$ constitute a discrete category of advanced materials that can offer unique advantages, as they combine properties of both the constituent components, i.e. excellent electrical and thermal conductivities of the $\mathrm{Cu}$, coupled with the low thermal expansion coefficient, and lubricating and corrosion-resistance properties of HTPAHs. ${ }^{28}$ In our previous work, ${ }^{29}$ we fabricated high strength carbon-copper $(\mathrm{C}-\mathrm{Cu})$ composites from a mixture of coal tar pitch-based ${ }^{26}$ selfsintering material (called green coke) and electrolyte grade $\mathrm{Cu}$ powder. It was observed that the HTPAHs-based $\mathrm{C}-\mathrm{Cu}$ composite exhibited comparatively good mechanical and electrical properties, as compared to graphite-Cu composites.

In the present investigation, we demonstrate the synthesis of nanocrystalline $\mathrm{Cu}$-coated $\mathrm{C}-\mathrm{Cu}$ nanocomposite, by the electroless technique, as a potential EMI shielding material. This synthesis technique is fast and reproducible. Here, the nanosized $\mathrm{Cu}$ coating on HTPAHs carbonaceous material takes place in situ, via a chemical reduction. The highly conductive interconnect network of $\mathrm{Cu}$ nanoparticles decreases the electrical resistivity of the C-Cu nanocomposites, as low as $\sim 0.14 \mathrm{~m} \Omega \mathrm{cm}$, which enhances the electrical conductivity of the hybrid nanocomposite. The maximum value of the EMI shielding effectiveness (SE) achieved for the $\mathrm{C}-\mathrm{Cu}$ nano-composite is $58.7 \mathrm{~dB}$ at $12.4 \mathrm{GHz}$, which is greater than the $\mathrm{SE}$ required for commercial applications $(\sim 30 \mathrm{~dB})$. In addition, the $\mathrm{Cu}$ nanoparticles-coated HTPAHs-based $\mathrm{C}-\mathrm{Cu}$ nanocomposites possess enhanced electrical conductivity and mechanical strength, thus making them suitable materials for next-generation EMI shielding applications on a large scale, especially in the $\mathrm{Ku}$ band of RF.

\section{Experimental}

\subsection{Material synthesis technique}

PAHs, in the form of coal tar pitch, with a softening point of 80$100{ }^{\circ} \mathrm{C}$, a quinoline insoluble content $<0.2 \%$ and a coking value $\sim 44-48 \%$, was heat treated (HT) to $500{ }^{\circ} \mathrm{C}$ for $3 \mathrm{~h}$ in $\mathrm{N}_{2}$ atmosphere, and then ball-milled for $5 \mathrm{~h}$ at $250 \mathrm{rpm}$, to obtain the carbonaceous precursor powder with an average particle size in the range $5-20 \mu \mathrm{m}$. The heat-treated PAHs (HTPAHs) powder was coated with $\mathrm{Cu}$ nanocrystalline particles by a chemicalreduction-based electroless coating technique. ${ }^{25}$ First, the surface of the HTPAHs powder was washed with acetone, then sensitized and activated with an acidic solution of tin chloride $\left(\mathrm{SnCl}_{2}, 2 \mathrm{~g} \mathrm{~L}^{-1}\right)$ and lead chloride $\left(\mathrm{PdCl}_{2}, 0.01 \mathrm{~g} \mathrm{~L}^{-1}\right)$, respectively, for 15 min each. After the above treatment, the HTPAHs powder was allowed to dry at room temperature. Second, a bath solution with $2 \mathrm{~L}$ of deionised water was separately prepared containing $\mathrm{Cu}$ ions, derived from the reduction of cupric sulphate $\left(\mathrm{CuSO}_{4} \cdot 5 \mathrm{H}_{2} \mathrm{O}, 20 \mathrm{~g}\right)$ along with a complexing agent (potassium sodium tartrate - $38 \mathrm{~g}$ ) for the coating of $\mathrm{Cu}$ nanoparticles. In order to get a uniform coating, the $\mathrm{pH}$ and operating temperature of the bath solution were maintained within the limit of 9-12 and $60-80{ }^{\circ} \mathrm{C}$, respectively, using sodium hydroxide solution. At an optimized temperature and $\mathrm{pH}$, hydrazine hydrate $(20 \mathrm{~mL})$ was added as a reducing agent.

In order to fabricate $\mathrm{C}-\mathrm{Cu}$ nanocomposites with a $\mathrm{Cu}: \mathrm{C}$ weight ratio of 0.50 and 1.28 , a calculated amount of the sensitized and activated HTPAHs powder was then added to the bath solution and stirred rigorously for $30 \mathrm{~min}$. Last, the Cu-coated HTPAHs powder was filtered and washed with distilled water, followed by drying. An inert atmosphere of nitrogen was maintained in the bath solution throughout the experiment to avoid the oxidation of $\mathrm{Cu}$. The HTPAHs (as such, batch $\mathrm{A})$ and $\mathrm{Cu}$-nanoparticles-coated HTPAHs powders $(\mathrm{Cu}: \mathrm{C}$ weight ratio of 0.50 and 1.28 , denoted by batches $\mathrm{B}$ and C, respectively) were moulded into the rectangular plates, of dimensions $40 \times 15 \times 5 \mathrm{~mm}^{3}$, using an hydraulic press at a pressure of $300 \mathrm{MPa}$. The moulds were then heat treated at $1000{ }^{\circ} \mathrm{C}$ for $2 \mathrm{~h}$ in an argon (Ar) atmosphere to obtain the final product. Fig. 1 shows a schematic of the coating mechanism of the $\mathrm{Cu}$ nanoparticles on HTPAHs via the electroless technique.

\subsection{Material characterisation techniques}

The bending strength of the synthesized samples was measured by a Universal Testing Machine (Instron, model 4411), and the electrical resistivity was determined using a laboratory developed four-probe apparatus. ${ }^{29}$ Phase identification and crystallite size measurements were carried out using X-ray powder diffraction (XRD) (Rigaku, MiniFlexII), and Fourier Transform Infra-Red Spectroscopy (FTIR) was conducted using Thermoscientific, Nicolet-5700. Scanning Electron Microscopy (SEM) (SEM, ZEISS-EVO MA10) and a transmission electron microscope (TEM) (FEI, Tecnai T30) were used to study the morphology and the microstructural characteristics. The EMI-SE was evaluated using a Vector Network analyzer (model-E8362B) on rectangular samples of dimensions $16 \times 8 \times 2.0 \mathrm{~mm}^{3}$.

\section{Results \& discussion}

Table 1 summarizes the physical and mechanical properties of HTPAHs (batch A) and HTPAHs-based $\mathrm{C}-\mathrm{Cu}$ nanocomposites with a $\mathrm{Cu}: \mathrm{C}$ ratio of 0.5 (batch B) and 1.28 (batch C). As expected, the green bulk density of batch A is low $\sim 1.28 \mathrm{~g} \mathrm{~cm}^{-3}$, compared to $\mathrm{C}-\mathrm{Cu}$ nanocomposites of batches $\mathrm{B}$ and $\mathrm{C}$, which is due to the high density of metallic $\mathrm{Cu}\left(8.9 \mathrm{~g} \mathrm{~cm}^{-3}\right)$, resulting in a maximum bulk density of $2.65 \mathrm{~g} \mathrm{~cm}^{-3}$ for batch C. After heat treatment to $1000{ }^{\circ} \mathrm{C}$, the sintered bulk density of HTPAHs increases to $1.65 \mathrm{~g} \mathrm{~cm}^{-3}$, which is due to the self-sintering properties of the HTPAHs, resulting in a high volume shrinkage $(29.7 \%)$ with a relatively low weight loss (9.39\%). The increase in sintered bulk density of batches B and C may also be attributed to the self-sintering properties of HTPAHs.

The $\mathrm{C}-\mathrm{Cu}$ nanocomposites (batches $\mathrm{B}$ and $\mathrm{C}$ ) exhibited an increased flexural strength, compared to HTPAHs (83 MPa, batch A) after heat treatment to $1000{ }^{\circ} \mathrm{C}$. The highest value of 

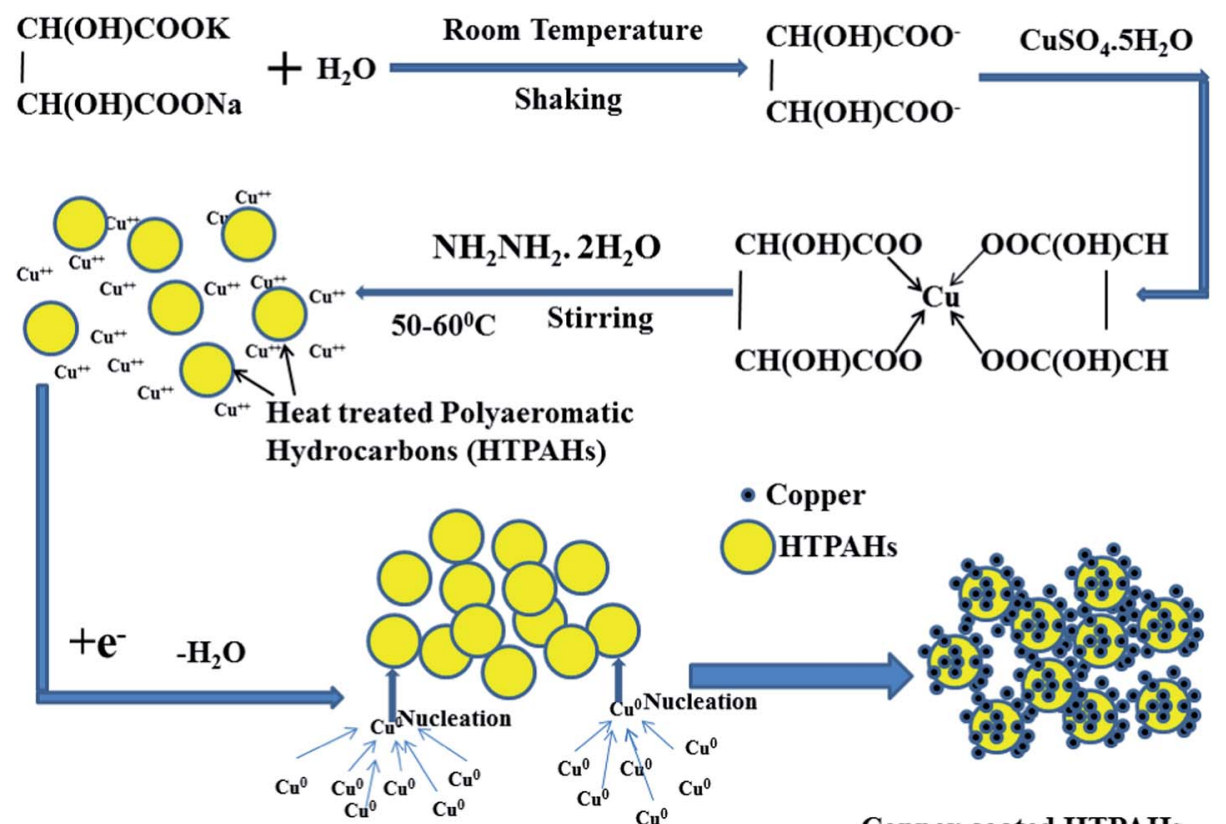

Copper coated HTPAHs

Fig. 1 Schematic of the synthesis mechanism for coating Cu nanoparticles on HTPAHs particles by electroless techniques.

Table 1 Characteristics of HTPAHs and nanocrystalline-Cu-coated HTPAHs nanocomposites

\begin{tabular}{|c|c|c|c|c|}
\hline \multirow[b]{2}{*}{ Characteristics } & \multirow[b]{2}{*}{ Heat treatment } & \multirow{2}{*}{$\begin{array}{l}\text { HTPAHs } \\
\text { Batch A Cu : C }(0: 100)\end{array}$} & \multicolumn{2}{|c|}{ HTPAHs-based C-Cu composites } \\
\hline & & & $\begin{array}{l}\text { Batch B Cu : C } \\
(33.6: 66.7)\end{array}$ & $\begin{array}{l}\text { Batch C Cu : C } \\
(56.3: 43.7)\end{array}$ \\
\hline Green bulk density $\left(\mathrm{g} \mathrm{cm}^{-3}\right)$ & $\mathrm{RT}$ & 1.28 & 1.90 & 2.65 \\
\hline Baked bulk density $\left(\mathrm{g} \mathrm{cm}^{-3}\right)$ & $1000{ }^{\circ} \mathrm{C}$ & 1.65 & 2.90 & 3.37 \\
\hline Weight loss (\%) & $1000^{\circ} \mathrm{C}$ & 9.39 & 4.94 & 3.18 \\
\hline Flexural strength (MPa) & $1000^{\circ} \mathrm{C}$ & 83 & 156 & 109 \\
\hline Shore hardness & $1000^{\circ} \mathrm{C}$ & 90 & 97 & 90 \\
\hline
\end{tabular}

$156 \mathrm{MPa}$ is observed for batch $\mathrm{B}$ samples with a $\mathrm{Cu}: \mathrm{C}$ ratio of 0.50 (see Table 1), and this enhancement is attributed to the self-sintering ability of PAHs, which results in solidification on heat treatment, and also due to the uniform dispersion of $\mathrm{Cu}$ nanoparticles in the carbon matrix, carried out via electroless coating technique, which helps in making a strong interconnecting network of $\mathrm{Cu}$ nanoparticles. ${ }^{30,31}$

However, a further increase in the $\mathrm{Cu}$ content $(\mathrm{Cu}: \mathrm{C}$ ratio of 1.28 (batch C)) shows an adverse effect on the flexural strength, as the quantity of HTPAHs-derived binder is insufficient, which is evident from the decrease in values of weight loss $(3.18 \%)$ and volume shrinkage (24.0\%). A similar trend was also observed for the shore hardness with increasing the $\mathrm{Cu}: \mathrm{C}$ ratio in these nanocomposites, due to the lower hardness of $\mathrm{Cu}$ as compared to carbon material. ${ }^{32}$ The electrical resistivity was calculated by eqn (1). The results clearly reveal that HTPAHs are highly resistive $(\sim 4.62 \mathrm{~m} \Omega \mathrm{cm})$, compared to $\mathrm{C}-\mathrm{Cu}$ nanocomposites (batches B and C), i.e. with 0.42 and $0.14 \mathrm{~m} \Omega \mathrm{cm}$, respectively, due to the highly conductive interconnecting network of $\mathrm{Cu}$ nanoparticles, which enhances the electrical conductivity of the hybrid nanocomposite.

$$
\rho=A V I I L
$$

where, $\rho=$ resistivity of the test-specimen $(\mathrm{Ohm} \mathrm{cm}), V=$ potential drop across the probe pins (volt), $A=$ area of crosssection of test-specimen $\left(\mathrm{cm}^{2}\right), I=$ magnitude of DC current (ampere), and $L=$ distance between the probe pins $(\mathrm{cm})$.

\subsection{XRD analysis}

The X-ray diffraction patterns of the $\mathrm{C}-\mathrm{Cu}$ nanocomposite (batch B), both after and before sintering, are shown in Fig. 2(a) and (b), respectively. A pronounced characteristic peak for carbon at $2 \theta=26.67^{\circ}$ was observed on heat treatment to $1000^{\circ} \mathrm{C}$ (Fig. 2(a)), as the crystallinity of HTPAHs-derived carbon increases upon annealing in an inert atmosphere. The same 


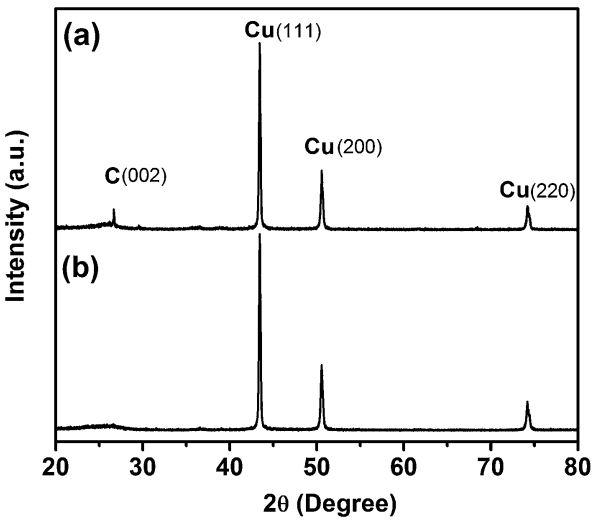

Fig. 2 XRD patterns for $\mathrm{C}-\mathrm{Cu}$ nanocomposite batch $\mathrm{B}(\mathrm{Cu}: \mathrm{C}=0.5)$ (a) after heat treatment to $1000^{\circ} \mathrm{C}$, and (b) before heat treatment

peak appears as a small hump at $2 \theta=23-28^{\circ}$ (see Fig. 2(b)), due to the presence of less-crystalline forms of carbon in the nanocomposite (batch B) at the green stage (without heat treatment). The main peaks corresponding to $\mathrm{Cu}$ appear at $2 \theta=$ $43.34^{\circ}, 50.61^{\circ}$, and $74.14^{\circ}$ representing (111), (200), and (222) planes, ${ }^{33}$ respectively, in both patterns apart from the characteristic peak of carbon. The average nanocrystalline $\mathrm{Cu}$ size, as determined by its prominent XRD peak by the Hall-Williamson method, was observed at $\sim 30 \mathrm{~nm}$. In addition to the above, no other peaks representing undesired phase formation, especially $\mathrm{CuO}$, were observed.

\subsection{FTIR spectroscopy}

Fig. 3 shows the FTIR spectra of carbonaceous precursor PAHs, after $500{ }^{\circ} \mathrm{C}$ (500HTPAH) and $1000{ }^{\circ} \mathrm{C}$ (1000НTPAH) heat treatment. The peak positions at $744,1218,1361,1439$, and $1737 \mathrm{~cm}^{-1}$, correspond to the aromatic $\mathrm{C}-\mathrm{H}$ out-of-plane vibration frequencies, aromatic ether $(\mathrm{C}-\mathrm{O})$, aromatic nitro $\left(\mathrm{NO}_{2}\right)$ compound, aromatic $\mathrm{C}=\mathrm{C}\left(\mathrm{sp}^{2}\right)$ ring, and the cyclic ether with a conjugation ring, respectively. ${ }^{34}$ However, on heat treatment to $500{ }^{\circ} \mathrm{C}$, the peak position at $744 \mathrm{~cm}^{-1}$ disappears,

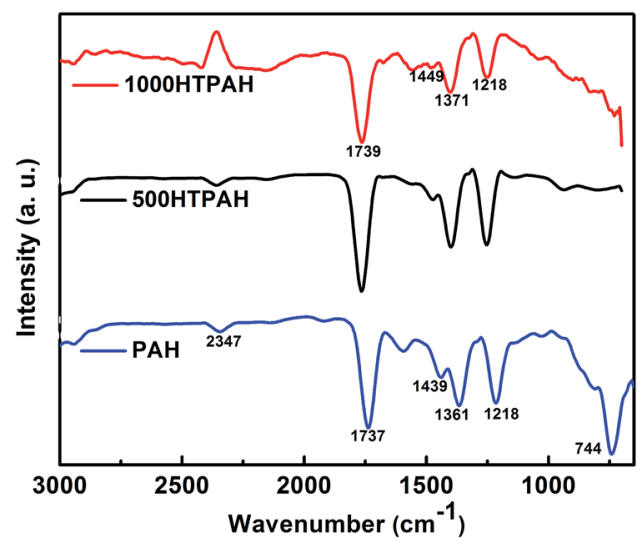

Fig. 3 Fourier Transform Infra-Red Spectroscopy (FTIR) analysis for PAHs, after $500{ }^{\circ} \mathrm{C}(500 \mathrm{HTPAH})$ and $1000{ }^{\circ} \mathrm{C}(1000 \mathrm{HTPAH})$ heat treatment. which confirms the removal of mono-substituted groups from the PAHs. The ortho-substitution of the aromatic ring band at about $744 \mathrm{~cm}^{-1}$ is due to absorption, which is much stronger than other types of substitution characteristic wavelengths. To be more precise, aromatic $\mathrm{C}-\mathrm{H}$ stretching bond is easily removed from the aromatic ring on heat treatment of the PAHs, owing to the condensation of the polyaromatic hydrocarbon molecules due to pi bond formation between the carbon atoms on the removal of hydrogen. A blue shift was observed for the peaks at, 1361,1439 , and $1737 \mathrm{~cm}^{-1}$, which may be due to the conversion of low molecular content into high molecular content. ${ }^{34} \mathrm{~A}$ broad peak at $2347 \mathrm{~cm}^{-1}$ may be attributed to $\mathrm{O}-\mathrm{H}$ stretching, due to overlapping of the $\mathrm{O}-\mathrm{H}$ acid group. The presence of the aromatic ring and the derivative peaks confirms the existence of polyaromatic hydrocarbon structures in HTPAHs.

\subsection{Surface morphology study}

The SEM image of $\mathrm{Cu}$ nanoparticles, obtained in the powder form through the electroless technique, is shown in Fig. 4(a). The flower-like structure observed in the micrograph is due to the agglomeration of $\mathrm{Cu}$ nanoparticles. The TEM image (Fig. 4(b)) of the same sample also agglomerated $\mathrm{Cu}$ nanoparticles exhibiting spherical morphology, with particle sizes in the range of $20-60 \mathrm{~nm}$, which is also supported by the XRD results. The selected area electron diffraction pattern (see the inset of Fig. 4(b)) clearly depicts the presence of a polycrystalline form of $\mathrm{Cu}$ nanoparticles with the corresponding planes 111, 200 , and 220.

The SEM micrograph (Fig. 5(a)) of HTPAHs (batch A) is seen to exhibit a uniform surface morphology, with some micropores that might be responsible for its low strength. The SEM image of the batch B sample in the powder form before moulding is shown in Fig. 5(b). A uniform coating of $\mathrm{Cu}$ nanoparticles through the electroless technique is clearly seen on the surface of the HTPAHs powder (batch B). For better clarification for the uniform coating of $\mathrm{Cu}$ nanoparticles on HTPAHs, see the ESI (Fig. 1S $\dagger$ ). The surface morphology of $\mathrm{C}-\mathrm{Cu}$ nanocomposite batch $\mathrm{B}(\mathrm{Cu}: \mathrm{C}=0.5)$ and batch $\mathrm{C}(\mathrm{Cu}: \mathrm{C}=1.28)$ after moulding and heat treatment to $1000{ }^{\circ} \mathrm{C}$ are shown in Fig. 5(c) and (d), respectively. Fig. 5(c) and (d) exhibit agglomeration in
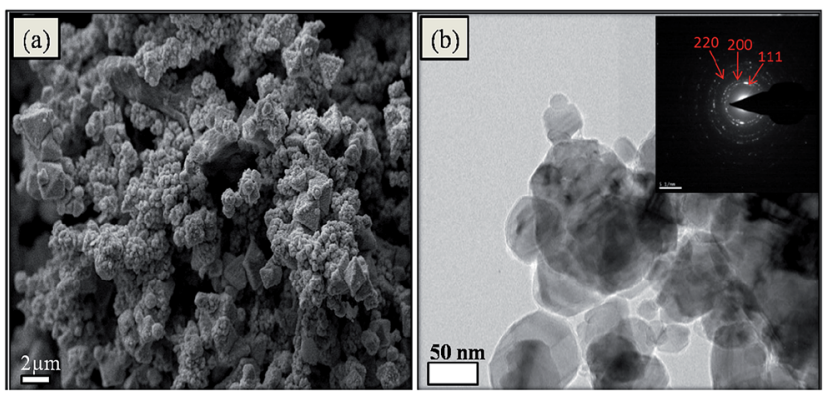

Fig. 4 Morphology of $\mathrm{Cu}$ nanoparticles synthesized using the electroloss technique in powder form (a) SEM; (b) TEM. The inset shows the selected area electron diffraction (SAED) pattern. 

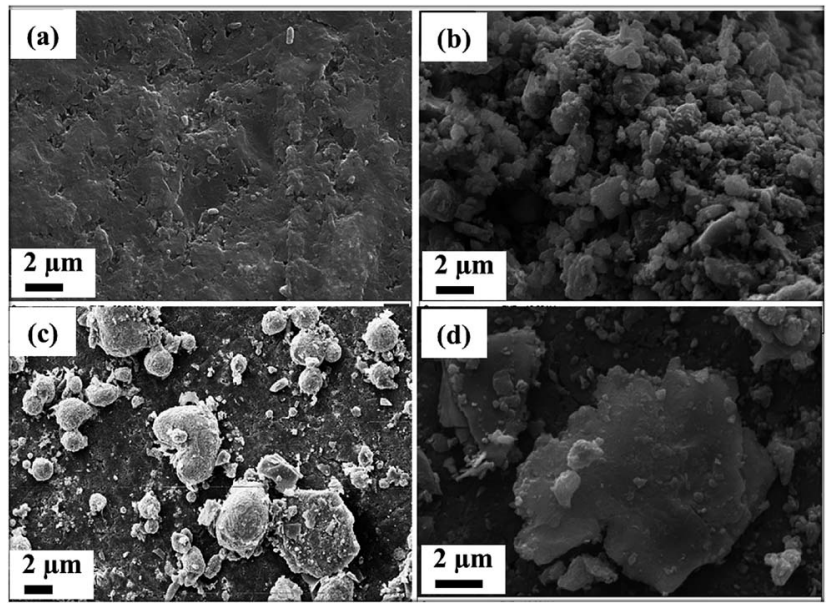

Fig. 5 SEM images of (a) HTPAHs heat treated at $1000^{\circ} \mathrm{C}$ (batch A); (b) nanocrystalline-Cu-coated HTPAHs powder (batch B (Cu: C =0.5)); (c) and (d) $\mathrm{C}$-Cu nanocomposites after moulding and heat treatment to $1000^{\circ} \mathrm{C}$ (batches $\mathrm{B}$ and $\mathrm{C}$ ), respectively.

some places, which may be due to heat treatment, as is also reported earlier for lead and bismuth nanoparticles. ${ }^{35}$

\subsection{EMI studies on HTPAHs and Cu-nanoparticles-coated HTPAHs}

In view of the fact that $\mathrm{Cu}$-nanoparticles-coated HTPAHs-based $\mathrm{C}-\mathrm{Cu}$ nanocomposites are conducting and possess very high mechanical strength, they were further analysed for their EMI shielding effectiveness (SE). In order to investigate the microwave attenuation of $\mathrm{C}-\mathrm{Cu}$ nanocomposites, the scattering parameters $\left(S_{11}\right.$ and $\left.S_{21}\right)$ were measured by a vector network analyzer to calculate the absorption $(A)$, reflection $(R)$, and transmission $(T)$ coefficients, and the absorption efficiency of the nanocomposites. In two port measurements, the $S$-parameters $S_{11}\left(S_{22}\right)$ and $S_{12}\left(S_{21}\right)$ represent the reflection and transmission coefficients given as $T=\left|S_{21}\right|^{2}=\left|S_{12}\right|^{2}$ and $R=\left|S_{11}\right|^{2}=$ $\left|S_{22}\right|^{2}$, while the absorption coefficient $(A)$ is defined as $A=1-$ $R-T$. Therefore, the effective absorbance $\left(A_{\text {eff }}\right)$ can be described as $A_{\text {eff }}=(1-R-T) /(1-R)$, with respect to the power of the incident EM wave. ${ }^{13}$ The plotted curves aim to show the excellent EM wave attenuation performances of the $\mathrm{C}-\mathrm{Cu}$ nanocomposites with changing frequency. Fig. 6(a)-(d) show the calculated $T$, absorption efficiency, and $R$ and $A$ values of the $\mathrm{C}-\mathrm{Cu}$ nanocomposites with a thickness of $2 \mathrm{~mm}$ in the frequency range of 12.4-18 GHz. The transmittance coefficient $(T)$ values of $\mathrm{C}-\mathrm{Cu}$ nanocomposites decrease with increasing $\mathrm{Cu}$ loading in $\mathrm{C}-\mathrm{Cu}$ nanocomposites. After $\sim 33 \mathrm{wt} \% \mathrm{Cu}$ loading, the transmittance coefficient is observed to be less than 0.001 , as shown in Fig. 6(c). In other words, due to the higher $A$ and $R$ coefficients, more of the EM wave is consumed by the $\mathrm{C}-\mathrm{Cu}$ nanocomposites, which leads to a more significant decrease of the $T$ values. The $R$ values of the $\mathrm{C}-\mathrm{Cu}$ nanocomposites at each weight ratio were close to $\sim 0.98$. The $R$ values of the $\mathrm{C}-\mathrm{Cu}$ nanocomposites increase with increasing $\mathrm{Cu}$ weight ratio. These plots show that the trend of the $R$ depends on the $\mathrm{Cu}$ (a)

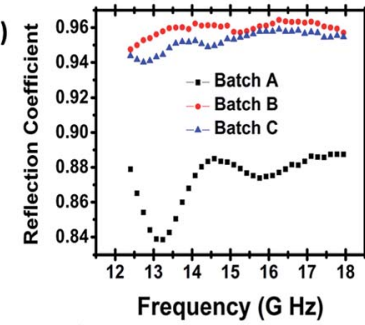

(c)

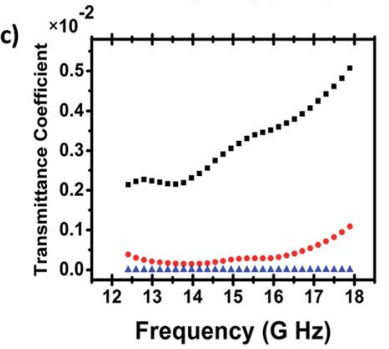

(b)

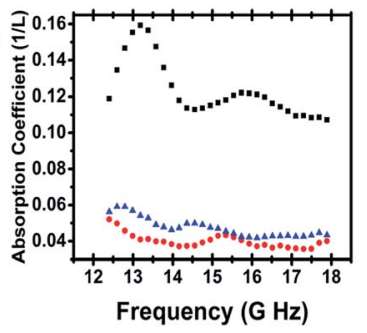

(d)

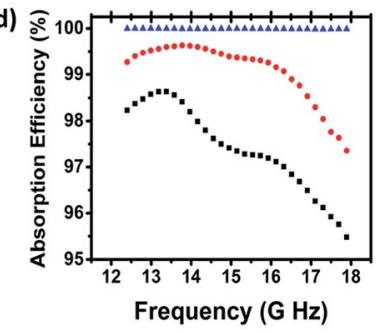

Fig. 6 Frequency dependence of (a) reflection coefficient, (b) absorption coefficient, (c) transmission coefficient, and (d) absorption efficiency for the as-synthesized C-Cu nanocomposite.

weight ratio and the frequency. Moreover, the absorption efficiency (\%) increases with the increasing weight \% of $\mathrm{Cu}$ in the $\mathrm{C}-\mathrm{Cu}$ nanocomposites (Fig. 5(d)). Nanocomposites batches B and $\mathrm{C}$ show \% absorption efficiencies of more than $99.9 \%$.

When the electromagnetic radiations are incident on a slab of EMI shielding material, phenomena, such as, absorption, reflection, and transmission are generally observed. The EMI SE of any material is the sum of the contributions of the absorption $\left(\mathrm{SE}_{\mathrm{A}}\right)$, reflection $\left(\mathrm{SE}_{\mathrm{R}}\right)$, and multiple reflections $\left(\mathrm{SE}_{\mathrm{M}}\right)$ of the $\mathrm{EM}$ energy. ${ }^{36-38}$ The variations observed in the absorbed, reflected, and total $\mathrm{SE}$ (i.e. $\mathrm{SE}_{\mathrm{A}}, \mathrm{SE}_{\mathrm{R}}$, and $\mathrm{SE}_{\mathrm{T}}$, respectively) over the frequency range of $12.4-18 \mathrm{GHz}$ (Ku-band) are plotted in Fig. 7(a)-(c) for all samples. The $\mathrm{SE}_{\mathrm{T}}$ is the sum of contribution from $\mathrm{SE}_{\mathrm{A}}, \mathrm{SE}_{\mathrm{R}}$, and the transmission or multiple reflection $\left(\mathrm{SE}_{\mathrm{M}}\right)$, which can be simply be expressed as $\mathrm{SE}_{\mathrm{T}}(\mathrm{dB})=\mathrm{SE}_{\mathrm{A}}+\mathrm{SE}_{\mathrm{R}}$ $+\mathrm{SE}_{\mathrm{M}}$, where $\mathrm{SE}_{\mathrm{M}}$ can be neglected when $\mathrm{SE}_{\mathrm{T}}>10 \mathrm{~dB},{ }^{39}$ hence, $\mathrm{SE}_{\mathrm{T}} \approx \mathrm{SE}_{\mathrm{A}}+\mathrm{SE}_{\mathrm{R}}$.

The values of $\mathrm{SE}_{\mathrm{A}}$ and $\mathrm{SE}_{\mathrm{R}}$ are found to vary from 17.5 to 46.1 dB (Fig. 7(a)), and 9.1 to $12.5 \mathrm{~dB}$ (Fig. 7(b)) for HTPAHs (batch A) and $\mathrm{C}-\mathrm{Cu}$ nanocomposites (batches $\mathrm{B}$ and $\mathrm{C}$ ), respectively. Thus, the corresponding value of $\mathrm{SE}_{\mathrm{T}}$ achieved for batch $\mathrm{A}$ is $26.1 \mathrm{~dB}$, and for nanocomposite batches $\mathrm{B}$ and $\mathrm{C}$ is 34.0 and $58.7 \mathrm{~dB}$, respectively. As the commercial applications of EMI shielding material requires a $\mathrm{SE}$ value of at least around $30 \mathrm{~dB},^{3}$ our Cu-coated HTPAHs-derived nanocomposites can be employed for commercial EMI shielding applications with an appropriate $\mathrm{Cu}$ nanoparticle loading. Our values of EMI shielding are much better than those of typical carbon materials, such as multi-wall carbon nanotubes anchored carbon fiber, ${ }^{40}$ graphene epoxy composite, ${ }^{41}$ and other carbon materials, ${ }^{9}$ etc. Fig. 7 further suggests that the $\mathrm{SE}_{\mathrm{T}}$ is mainly dominated by absorption, while the contribution due to reflection $\left(\mathrm{SE}_{\mathrm{R}}\right)$ is comparatively low. Usually, the primary mechanism of EMI shielding is via reflection of the electromagnetic radiation incident on the shield, which is a consequence of interaction 

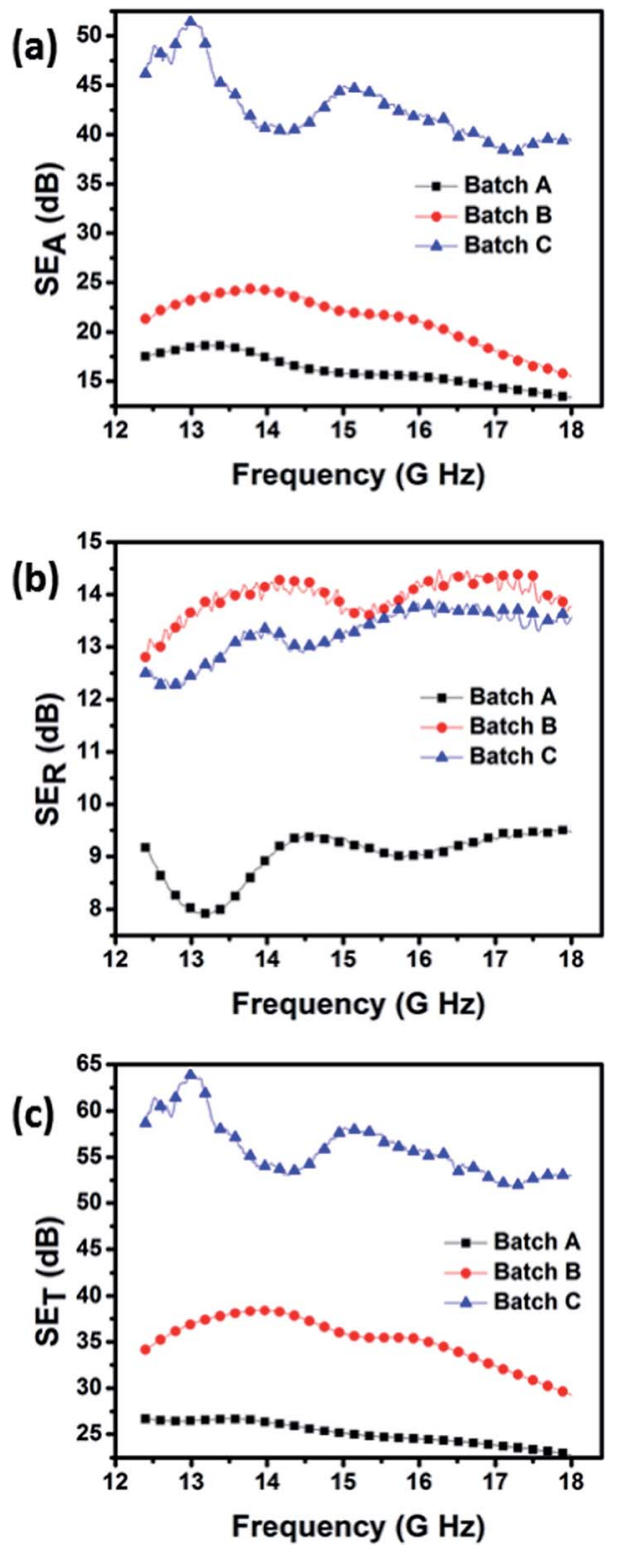

Fig. 7 Frequency dependent EMI shielding effectiveness (SE) of HTPAHs (batch A) and Cu-coated HTPAHs nanocomposite (batches B and C) via (a) absorption $\left(S_{A}\right)$, (b) reflection $\left(S E_{R}\right)$, and (c) corresponding total $\mathrm{SE}\left(\mathrm{SE}_{\mathrm{T}}\right)$.

between EMI radiation and the free electrons available on the surface of the conducting shield. ${ }^{9}$ EMI shielding via absorption is mainly a secondary mechanism, whereby electric dipoles in the shield material interact with electromagnetic waves. Moreover, EMI shielding using highly conducting materials, such as, carbon nanotubes, is mainly due to reflection rather than absorption. ${ }^{42}$ On the other hand, conducting nanocomposites provide EMI shielding predominantly due to absorption, owing to the presence of electric dipoles. ${ }^{\mathbf{4 3 , 4 4}} \mathrm{A}$ similar phenomenon in our Cu-coated HTPAHs nanocomposite samples is envisaged, due to their intrinsic conducting properties.

Furthermore, the values of $\mathrm{SE}_{\mathrm{A}}$ for Cu-coated HTPAHs nanocomposite (batches $\mathrm{B}$ and $\mathrm{C}$ ) are found to be in the range of
21.3-15.5 and 46.2-39.4 dB, respectively, which are higher than the pristine HTPAHs batch A (17.5-13.3 dB) over the entire observed frequency range (see Fig. $7(\mathrm{a})$ ). The same trend was also observed in the values of $\mathrm{SE}_{\mathrm{R}}$ (see Fig. $7(\mathrm{~b})$ ). It can be inferred that samples having a high loading of $\mathrm{Cu}$ nanoparticles show enhanced values of $\mathrm{SE}_{\mathrm{A}}$ and $\mathrm{SE}_{\mathrm{R}}$. Also, as shown in Fig. 7(c), in nanocomposite batches $\mathrm{B}$ and $\mathrm{C}$, the values of $\mathrm{SE}_{\mathrm{T}}$ are in the range of 34.1-29.2 and 58.6-53.1 dB, respectively, for a $2 \mathrm{~mm}$ thick sample, which is again higher than batch $\mathrm{A}$ (i.e. 26.7-22.8 dB) in the Ku-band. The variation in electromagnetic shielding as a function of thickness, done explicitly for batch $\mathrm{C}$, are plotted and discussed under Fig. 3S, as shown in the ESI. $\dagger$ The SE (dB) was found to increase as the thickness was varied from 0.5 to $2.0 \mathrm{~mm}^{45}$ The thickness $(t)$ of sample that can satisfy the minimum requirement $(\mathrm{SE} \sim 30 \mathrm{~dB})$ for techno-commercial applications was found to be $0.5 \mathrm{~mm}<t<1.0 \mathrm{~mm}$. Hence, it is proposed that a higher loading of $\mathrm{Cu}$ nanoparticles in carbon nanocomposites made via a novel technique of electroless coating may enhance the conductivity and electric polarization of the material, which thus induces dipolar and electric polarization in the presence of microwaves, resulting in an enhanced EMI SE.

In order to make a better comparison, the microwave shielding ability of $\mathrm{C}-\mathrm{Cu}$ nanocomposites have been further evaluated using complex permittivity $\left(\varepsilon^{\prime}-j \varepsilon^{\prime \prime}\right)$ and complex permeability $\left(\mu^{\prime}-j \mu^{\prime \prime}\right)$, as shown in Fig. 8 . The real part of the EM parameters $\left(\varepsilon^{\prime}, \mu^{\prime}\right)$ is a measure of polarization occurring in the material and symbolizes the storage ability of the electric and magnetic energy, while the imaginary part $\left(\varepsilon^{\prime \prime}, \mu^{\prime \prime}\right)$ denotes the dissipated electric and magnetic energy. Among all the $\mathrm{C}-\mathrm{Cu}$ nanocomposites, batch $\mathrm{C}$ has more importance because it shows the highest SE (58 dB). In Fig. 8, the values of $\varepsilon^{\prime}, \varepsilon^{\prime \prime}, \mu^{\prime}$, and $\mu^{\prime \prime}$ for batch $\mathrm{C}$ are in the range of 52.65-34.71, 28.85-30.58, $0.62-0.70$, and $0.20-0.36$, respectively. For non-magnetic materials, permittivity and its loss mechanism are very important parameters. The real permittivity (dielectric constant $\varepsilon^{\prime}$ as shown in Fig. 8(c)) shows a decrease in the frequency range of 12.4 to $18 \mathrm{GHz}$, while the imaginary permittivity (dielectric loss $\left.\varepsilon^{\prime \prime}\right)$ shows two broad humps in the range of 12.4-13.9 and 14 to 15.8 GHz. Therefore, the dielectric loss mechanism of batch $\mathrm{C}$ is mainly attributed to polarization and multiple reflections or multiple scattering. The polarization mechanism in the sample is space charge polarization, rather than electric, dipolar, or ionic polarization. Space-charge, or interfacial polarization, occurs when charge carriers are present in the sample, which can migrate an appreciable distance and get trapped. This process always results in a distortion of the macroscopic field. The interfaces between carbon and $\mathrm{Cu}$ nanoparticles enhance the interfacial polarization in HTPAHs and $\mathrm{Cu}$ nanoparticles in the $\mathrm{C}-\mathrm{Cu}$ nanocomposite, and can act as scattering or reflection centers, which further enhances the dielectric losses.

The improved microwave shielding performance of the C-Cu-based nanocomposites can be attributed to dielectric losses. The natural resonance, dipole polarization and its relaxation, and polarization of charge carriers, like electrons, and their relaxation simultaneously contribute to the dielectric loss mechanism during activation by an EM wave. A schematic 


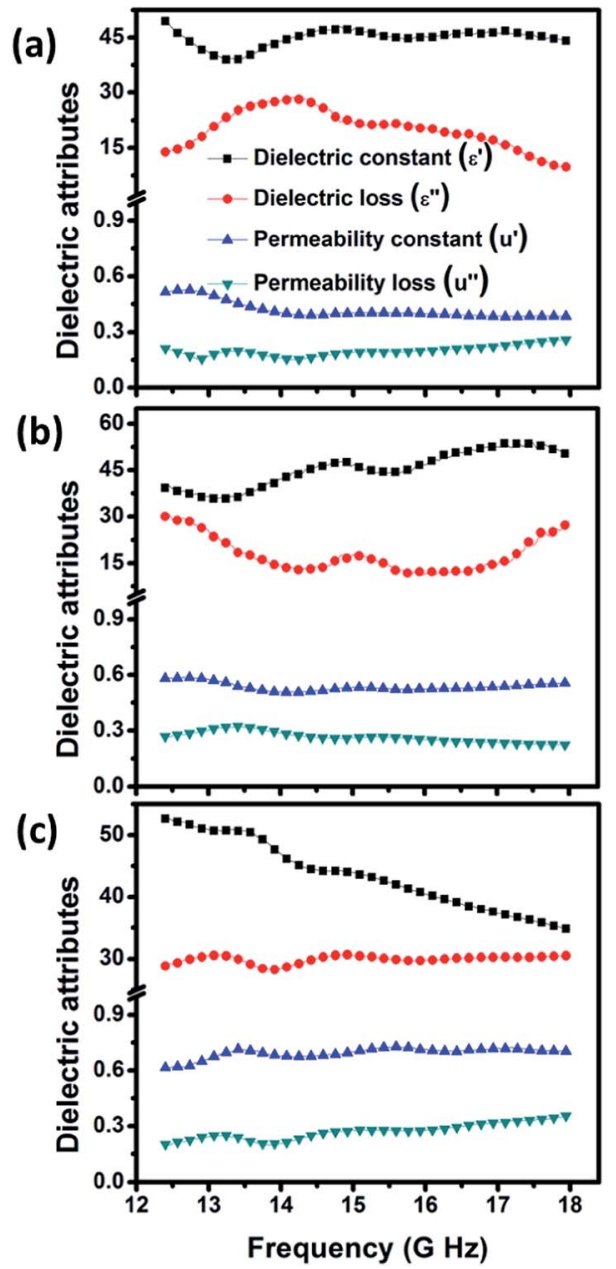

Fig. 8 Behaviour of dielectric attributes of batch A (a), batch B (b), and batch $C$ (c), as a function of frequency.

representation of the microwave absorption mechanisms, as discussed above, is presented in Fig. 9. It is evident from the EMI shielding results that these $\mathrm{C}-\mathrm{Cu}$-based nanocomposites

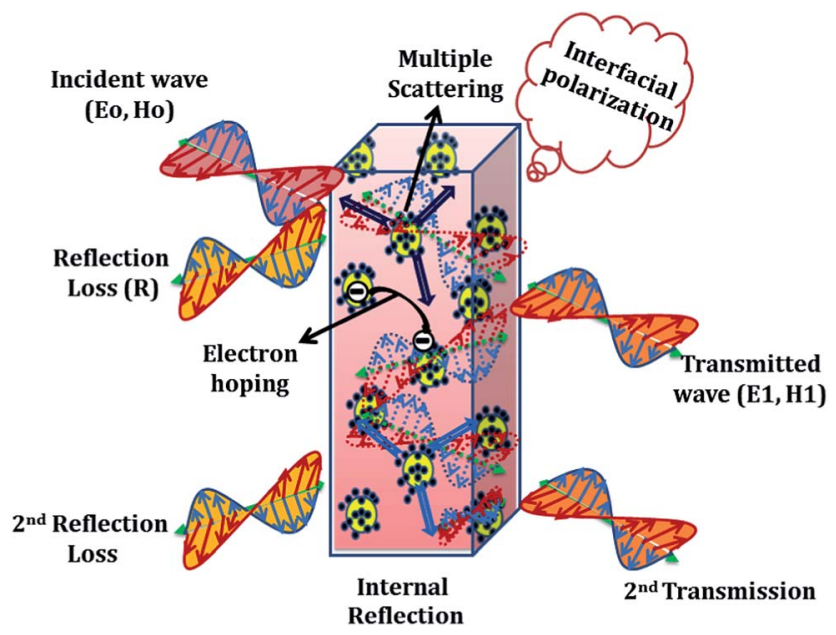

Fig. 9 Schematic presentation of the shielding mechanism of $\mathrm{Cu}$ nanoparticles-coated HTPAHs. are excellent shielding materials with good mechanical strength. Furthermore, they were synthesized by a simple, costeffective technique and can be used for large-scale EMI shielding applications where a high SE is desired.

\section{Conclusion}

This work reports the fabrication of $\mathrm{C}-\mathrm{Cu}$ nanocomposites (20$60 \mathrm{~nm}$ ) by coating HTPAHs with $\mathrm{Cu}$ nanoparticles for use as an effective EMI shielding material. Nanoparticles of $\mathrm{Cu}$ were coated onto self-sintered HTPAHs powders by the electroless technique, and the resulting $\mathrm{C}-\mathrm{Cu}$-based nanocomposites exhibited significantly improved bulk density, electrical resistivity, and bending strength. A uniform dispersion of $\mathrm{Cu}$ nanoparticles in the nanocomposite forms an interconnected network, which results in the high electrical conductivity, and leads to an enhancement in EMI SE. The network of $\mathrm{Cu}$ nanoparticles in HTPAHs improves the interface density, leading to space charge accumulation in heterogeneous media that promotes the level of impedance matching for better microwave absorption. $\mathrm{Cu}$ nanoparticles decoration significantly increases the EMI SE of HTPAHs from 26.7 to $58.7 \mathrm{~dB}$ at $12.4 \mathrm{GHz}$ for a $2 \mathrm{~mm}$ thick sample. The observed SE is mainly contributed by $\mathrm{SE}$ due to absorption ( $\mathrm{SE}_{\mathrm{A}}$ is $\sim 4$ times $\mathrm{SE}_{\mathrm{R}}$ ). The origin of the high SE has been shown to be mainly due to absorption of the incident EM radiation. The remarkable improvement in SE of HTPAHs-based $\mathrm{Cu}$ nanocomposites, coupled with their high mechanical properties, make them promising materials for next-generation EMI shielding applications, especially in the $\mathrm{Ku}$ band of the RF range.

\section{Acknowledgements}

The authors are thankful to Prof. R. C. Budhani, Director, CSIRNational Physical Laboratory, for his keen interest in this work. Thanks are also to Mr Jay Tavale, Dr V. N. Singh for their valuable help in X-ray and SEM/TEM studies. One of the authors (Anil Kumar) gratefully acknowledges the financial assistance from MNRE, India in form of senior research fellowship.

\section{References}

1 Z. Chen, C. Xu, C. Ma, W. Ren and H.-M. Cheng, Adv. Mater., 2013, 25, 1296-1300.

2 S. Yang, K. Lozano, A. Lomeli, H. D. Foltz and R. Jones, Composites, Part A, 2005, 36, 691-697.

3 N. Li, Y. Huang, F. Du, X. He, X. Lin, H. Gao, Y. Ma, F. Li, Y. Chen and P. C. Eklund, Nano Lett., 2006, 6, 1141-1145.

4 M. H. Al-Saleh and U. Sundararaj, Carbon, 2009, 47, 17381746.

5 A. P. Singh, M. Mishra, P. Sambyal, B. K. Gupta, B. P. Singh, A. Chandra and S. K. Dhawan, J. Mater. Chem. A, 2014, 2, 3581-3593.

6 J. Wang, C. Xiang, Q. Liu, Y. Pan and J. Guo, Adv. Funct. Mater., 2008, 18, 2995-3002.

7 K. Lakshmi, H. John, K. T. Mathew, R. Joseph and K. E. George, Acta Mater., 2009, 57, 371-375. 
8 A. Celzard, E. McRae, G. Furdin and J. F. Marêché, J. Phys.: Condens. Matter, 1997, 9, 2225.

9 D. D. L. Chung, Carbon, 2001, 39, 279-285.

10 T. K. Gupta, B. P. Singh, S. R. Dhakate, V. N. Singh and R. B. Mathur, J. Mater. Chem. A, 2013, 1, 9138-9149.

11 K. Singh, A. Ohlan, V. H. Pham, B. R. S. Varshney, J. Jang, S. H. Hur, W. M. Choi, M. Kumar, S. K. Dhawan, B.-S. Kong and J. S. Chung, Nanoscale, 2013, 5, 2411-2420.

12 R. Kumar, S. R. Dhakate, T. Gupta, P. Saini, B. P. Singh and R. B. Mathur, J. Mater. Chem. A, 2013, 1, 5727-5735.

13 Q. Liu, J. Gu, W. Zhang, Y. Miyamoto, Z. Chen and D. Zhang, J. Mater. Chem., 2012, 22, 21183-21188.

14 M. H. Al-Saleh, W. H. Saadeh and U. Sundararaj, Carbon, 2013, 60, 146-156.

15 J. Joo and C. Y. Lee, J. Appl. Phys., 2000, 88, 513-518.

16 J. Wu and D. D. L. Chung, Carbon, 2003, 41, 1313-1315.

17 Y. Chen, Y. Li, M. Yip and N. Tai, Compos. Sci. Technol., 2013, 80, 80-86.

18 A. P. Singh, B. K. Gupta, M. Mishra, Govind, A. Chandra, R. B. Mathur and S. K. Dhawan, Carbon, 2013, 56, 86-96.

19 A. P. Singh, M. Mishra, A. Chandra and S. K. Dhawan, Nanotechnology, 2011, 22, 465701.

20 A. A. Al-Ghamdi and F. El-Tantawy, Composites, Part A, 2010, 41, 1693-1701.

21 Q. Liu, D. Zhang and T. Fan, Appl. Phys. Lett., 2008, 93, 013110.

22 S.-S. Tzeng and F.-Y. Chang, J. Mater. Sci. Eng. A, 2001, 302, 258-267.

23 S. F. Moustafa, S. A. El-Badry, A. M. Sanad and B. Kieback, Wear, 2002, 253, 699-710.

24 L. Liu, Y. Tang, H. Zhao, J. Zhu and W. Hu, J. Mater. Sci., 2008, 43, 974-979.

25 R. Sharma, R. C. Agarwala and V. Agarwala, Appl. Surf. Sci., 2006, 252, 8487-8493.

26 M. L. Machado, P. W. Beatty, J. C. Fetzer, A. H. Glickman and E. L. Mcginnis, Toxicol. Sci., 1993, 21, 492-499.

27 T. Hamada, T. Nishida, Y. Sajiki, M. Matsumoto and M. Endo, J. Mater. Res., 1987, 2, 850-857.

28 C. L. Mantell, Carbon and graphite handbook, Interscience Publishers, 1968.
29 A. Kumar, M. Kaur, R. Kumar, P. Sengupta, V. Raman, G. Bhatia and K. Sood, J. Mater. Sci., 2010, 45, 1393-1400.

30 Y. Zhan, M. Lavorgna, G. Buonocore and H. Xia, J. Mater. Chem., 2012, 22, 10464-10468.

31 C. Wu, X. Huang, G. Wang, L. Lv, G. Chen, G. Li and P. Jiang, Adv. Funct. Mater., 2013, 23, 506-513.

32 P. Jenei, E. Y. Yoon, J. Gubicza, H. S. Kim, J. L. Lábár and T. Ungár, J. Mater. Sci. Eng. A, 2011, 528, 4690-4695.

33 N. Jha and S. Ramaprabhu, J. Phys. Chem. C, 2008, 112, 93159319.

34 M. D. Guillen, M. J. Iglesias, A. Dominguez and C. G. Blanco, Energy Fuels, 1992, 6, 518-525.

35 H. Jiang, K.-s. Moon, F. Hua and C. P. Wong, Chem. Mater., 2007, 19, 4482-4485.

36 A. P. Singh, P. Garg, F. Alam, K. Singh, R. B. Mathur, R. P. Tandon, A. Chandra and S. K. Dhawan, Carbon, 2012, 50, 3868-3875.

37 M. Ashokkumar, N. T. Narayanan, B. K. Gupta, A. L. M. Reddy, A. P. Singh, S. K. Dhawan, B. Chandrasekaran, D. Rawat, S. Talapatra, P. M. Ajayan and P. Thanikaivelan, ACS Sustainable Chem. Eng., 2013, 1, 619-626.

38 M. Mishra, A. P. Singh and S. K. Dhawan, J. Alloys Compd., 2013, 557, 244-251.

39 A. P. Singh, A. K. S., A. Chandra and S. K. Dhawan, AIP Adv., 2011, 1, 022147.

40 B. P. Singh, P. Bharadwaj, V. Choudhary and R. B. Mathur, Appl. Nanosci., 2013, 1-8.

41 J. Liang, Y. Wang, Y. Huang, Y. Ma, Z. Liu, J. Cai, C. Zhang, H. Gao and Y. Chen, Carbon, 2009, 47, 922-925.

42 Y. Yang, M. C. Gupta, K. L. Dudley and R. W. Lawrence, Nano Lett., 2005, 5, 2131-2134.

43 R. C. Che, L. M. Peng, X. F. Duan, Q. Chen and X. L. Liang, Adv. Mater., 2004, 16, 401-405.

44 P. Sambyal, A. P. Singh, M. Verma, M. Farukh, B. P. Singh and S. K. Dhawan, RSC Adv., 2014, 4, 12614-12624.

45 T. K. Gupta, B. P. Singh, V. N. Singh, S. Teotia, A. P. Singh, I. Elizabeth, S. R. Dhakate, S. K. Dhawan and R. B. Mathur, J. Mater. Chem. A, 2014, 2, 4256-4263. 